\title{
The Video Game from the Perspective of Positive Psychology
}

\author{
Shuang Liang, Honghan Li, Xiaojun Yang \\ School of Educational Science, Guangxi Normal University, Guilin, China \\ Email: Ishuang1219@163.com
}

Received July 2014

\begin{abstract}
In recent years, video games have become one of the primary means of people's daily entertainment. With the diversification of video gaming platform and the enrichment of the contents, the impact of video games on people's mental health and behavior is increasing, and thus becomes a hot research area of psychology. Traditional psychology has done a lot of research on the negative impact of video games, but the advent of positive psychology offers a new research perspective of the video game. This paper presents a review of the research focusing on the video games on people's emotions, positive personal trait quality positive personal trait, relationships from the perspective of positive psychology, and offers suggestion for future video games design.
\end{abstract}

\section{Keywords}

Positive Psychology, Video Games, Positive Effect, Video Game Design

\section{Positive Steering of Traditional Psychology}

Positive psychology is a new branch of psychology which uses scientific understanding and effective measures of intervention to lead to satisfactory life, rather than just treating mental illness [1].

It was rooted in the humanistic psychology of the 20th century, which focused on the study of happiness and a sense of achievement. Then in 1998, Martin Seligman, president of the American Psychological Association chose it as the theme for his term made it as a new area of psychology. In 10 years of research in the late 20th century, psychologists began to focus on the prevention of mental disorders, and further promote the development of positive psychology. In January 2000 Seligman and Csikzentmihalyi published "Positive Introduction to Psychology", as a symbol; a growing number of psychologists began to get involved in research in this area, and gradually formed a positive psychology movement [2].

Positive Psychology is focused on three different issues: positive emotions, positive individual traits, and positive institutions. Positive emotions are concerned with individual's past, present, and future, they advocate people should be content with the past, enjoy themselves in the present and have hope for the future. Positive individual traits relate to one's strengths and virtues. Finally, positive institutions are based on strengths to better a community of people.

Traditional psychology paid more attention on the negative effect of the video games. Exposure to violent video games will increase aggressive behavior in both the short term (e.g., laboratory aggression) and the long 
term (e.g., delinquency) [3].The development of positive psychology is to give us a new perspective. With the further study of video games, more and more researchers have begun to shift the focus to the positive field of video games. However, the current research focus more on positive effects in education, but less involved in the positive impact on people's real-life role in mental health.

\section{Positive Psychological Value of Video Games}

\subsection{Effect on Positive Emotion of Video Games}

The researches of positive emotions in positive psychology focus on subjective well-being. Playing video games is conducive to arouse the emotion experience. Gamers had significantly better emotional experience, higher levels of well-being, and to some extent, less depression compared to non-gamers [4].

The players in the video game can give vent to feelings, exchange ideas, which is conducive to promoting the healthy development of emotional and psychological state [5]. Entertainment of video games also can enrich people's emotional experience; individuals can not only gain self-satisfaction and a sense of control while playing video games, but also achieve emotional sublimation. For example, the Honorable company of Japan produced a game called Uncharted Waters, the game can lead the player to learn tolerance, planning and improve the leadership of them by offering players authority to arrange the positions of their partners. It provides different ways to get the emotion experience.

In the process of overcoming difficulties and game upgrading, the player can acquire a kind of indeed satisfaction detached from reality and enjoy the sense of self-efficacy and social identity which are difficult to get in real life, it conducive to shift the emotional states from negative to positive, and enhance the well-being of the gamers [6].

\subsection{Effect on Positive Quality of Video Games}

Video games can improve players' intelligence and cognitive traits. At present, most of the video games on the market contain a wealthy knowledge of social and cultural life, and can boost the level of their knowledge. The game Uncharted Waters collects many ports and islands in Asia, Europe, America and other places in 16th century, players in the game can find different parts of the historical sites and cultural landscapes, it widens the geographical knowledge of players. Meanwhile, to some extent, video games can improve individual's critical learning abilities and creativity. Since players need to learn the rules and the special symbolic meaning in the game, players can think critically the game as a system and a well-designed space, rather than a simple game environment [7]. Critical and creative thinking in the context of the game holds an important position in human psychological development and in the formation of thinking.

Besides, video games have an important affect on people's behavior, moral behavior education which based on the emotion can make use of the positive effect of video games. Positive video games can promote virtue and strength of players, which is the core of positive qualities of individuals. Digital games lab in Taiwan Normal University had extend the influence of video games on players to educational practice, found it useful for helping students to establish an appropriate sense of morality and values [8].

\subsection{Effect on Positive Interpersonal Relationship of Video Games}

With the popularity of video games, a growing concern for interpersonal indifference appears. Studies have shown that playing video games does not affect the relationships between people. Instead, the pattern of interaction and linkages between people has been established in a new way [9]. Video games is not a simple course of the game, to a greater extent, it is a process of integration of social interaction.

From the single game, the game players are generally discussed strategy and cooperated with the other for social interaction, and for network video games, the game itself will need to interact with other players during the game, you can chat with other people, and you can form virtual-teams game in the interactive process. Extended to real life, due to the formation of a pleasurable experience and cooperation, a lot of players in the game extend to life and become good friends [10].

In addition, video games can also help people learn how to get along with people, in order to help promote the development of positive interpersonal relationships. An earlier study [11] insisted that too many young people who spent most of their time in entertainment center are not playing the game, but putting a virtual video game 
scene as a social gathering space. Gamers can share the game experience and resources to create common activities through websites, forums and other communication platform. So relationship between video games and gamers is not a simple human-computer interaction model, but a relationship which contains discussion, collaboration and reflection on the process of peer group [12].

\section{Design of Video Games in the Perspective of Positive Psychology}

The current video game designed to be fighting and violence to attract players, but this design will cause a negative impact. If you can explore the physiological and psychological mechanisms gaming entertainment and gaming experience from various levels of positive psychology, and the importance of enhancing positive emotions, quality, relationships, players will be able to promote the healthy development which is largely psychological.

\subsection{Intensifying Game's Content of Learned Optimism}

Optimistic attitude can be obtained through learning. Seligman believes that optimism is the lasting, widespread and internal attribution to the good things when individual's interpreting the events that have occurred, while the bad ones, they have short, specific and external attribution [15]. This attribution can be acquired through learning, that the interpretation of the event changes from negative to positive attribution way.

Therefore, we can consider to injecting some factors in video games which allow people to learn optimism to situational factors on people's cognition, emotion, and physiological arousal. Firstly, set an optimism story as the backward of the game, although the story is simple, its' meaning in immersing and engaging the player is extremely important. The role of the optimism story can be educative. Secondly, the video games can be designed to encourage students to solve the problems with an optimistic attitude. Setting personal goals, gathering information, discovering and doing some modification of the negative thoughts should be involved in the game (Rollings \& Adams, 2003). Lastly, optimistic attitude can be trained by example learning, and players can be more optimism by communicating with other partners. It make the game not only allows players to experience the fun, but also learned a positive and optimistic attitude towards life.

\subsection{Intensifying Game’s Positive Emotional State with Flow}

Choosing a suitable content of optimism is only one aspect in the design. Positive psychology still focuses on positive emotions and experiences, such as subjective well-being, and attention. The emotional experience is the source of the positive and optimistic emotion. Flow can arouse the positive emotion as a psychological statement [13], so that the game designers can add it to video games.

Flow describes a state of someone complete focusing himself on the activity and forgetting everything outside, it so refers to the optimal experience. Game designers should take the flow theory into consideration, using positive images and wonderful voice to generate a positive and steady statement in the process will be successful and engaging [5].

Adding the flow experience into the game process, players involving with the goal driven activity forget time, place, nearly himself so that nothing else seems to matter. Past research has shown that attention get from flow state has positive impact on getting positive emotion [14]. On the other band, Results indicate that in general, players evaluate their performance worse if they have been confronted with harder game difficulty. Game designers should pay more attention to matching the challenges with a player's skill level with the inspiration of flow.

\subsection{Intensifying Game's Interactive Functions}

Some scholars believe that the game is often the booster among the social, communication and peer group activities [15]. Whether it is from the game or from the promotion and marketing of game, the interaction is an essential factor. A good game should be built on the reality of communication.

Nowadays, video games offer a virtual environment for players, but if one plays as a role in the game, he/she is a part of it, and is getting still closer to reality. Video games should be designed to connect to everyday life and the friends circle, so that it can keep the relationship with friends and everyday life experience. Such con- 
crete experience is the heart of the video game design approach in which knowledge is constructed, not transmitted, as a result of experiencing and interacting with the environment.

Besides, games that encompass the methods of how to maintain social relation better are believed to hold the potential to render good results and make it more enjoyable, more interesting, and, thus, more effective.

Finally, game developers can perform interactive games designed for certain specific groups. For example, depression, and get the treatment methods of positive psychology into video games, so the treatment of depression in patients with entertainment in the game, so that they get mental health training and development.

\section{Conclusion}

Impact of video games has been a controversial topic, although there may be many problems of its own, we cannot always staring at its negative effects, because blindly restrictions and negative resist does not solve the problem fundamentally. We should try to proceed from the perspective of positive psychology, probe the research point of video games that meet the mental health needs of people, and try to explore its positive side. The Positive Psychology's father Seligman also pointed out that creating good video games can improve human well-being. He believes that video games can promote people's emotions, quality and relationships in a positive direction. Positive impact and application of video games have just started in China, we need many people work together to promote human development, and turn it into mankind's spiritual feast.

\section{References}

[1] Seligman, E.P. and Csikszentmihalyi, M. (2000) Positive Psychology: An Introduction. American Psychologist, 55, 514. http://dx.doi.org/10.1037/0003-066X.55.1.5

[2] Time Magazine’s Cover Story in the Special Issue on “The Science of Happiness”, 2005 (PDF). Retrieved 2011-02-07.

[3] Anderson, C.A. and Dill, K.E. (2000). Video Games and Aggressive Thoughts, Feelings, and Behavior in the Laboratory and in Life. Journal of Personality and Social Psychology, 78, 772-790. http://dx.doi.org/10.1037/0022-3514.78.4.772

[4] Jason, C.A., McLaughlin, A.C., Trujillo, A., Whitlock, L.A., LaPorte, L. and Gandy, M. (2013) Successful Aging through Digital Games: Socioemotional Differences between Older Adult Gamers and Non-Gamers. Computers in Human Behavior, 29, 1302-1306. http://dx.doi.org/10.1016/j.chb.2013.01.014

[5] Zhao, Y. L., He, Y. and Zheng Y. (2011) Negative Effects of Video Games and Disputes. Advances in Psychological Science, 19, 1788-1797

[6] Tian, W. (2009) The Educational Potential of Online Games from a Psychological Perspective. Journey of Chongqing University Science and Technology, 2, 214-215.

[7] Jackson, L.A. (2011) Information Technology Use and Creativity: Findings from the Children and Technology Project. Computers in Human Behavior, 28, 370-376. http://dx.doi.org/10.1016/j.chb.2011.10.006

[8] Wang, D. and Liu, D.H. (2012) Review of Correlative Research of Young People’s Network Game. Advertising Panorama. 12, 53-61.

[9] Staffan, B. (2008) Games, Gamers, and Gaming: Understanding Game Research. Proceedings of the 12th International Conference on Entertainment and Media in the Ubiquitous Era.

[10] Shang, J.J. and Zhuang, S.Y. (2008) Value Research of the Game’s Applications in Education. Distance Education Journal, 6, 63-68.

[11] Greenfield, P.M. (1984) Mind and Media: The Effects of Television. Computers and Video Games. Harvard University Press.

[12] Williamson, B. and Facer, K. (2003) More than “Just a Game”: The Implications for Schools of Children’s Computer Games Communities. Education, Communication and Information, 4, 253-268.

[13] Csikszentmihalyi, M. (1991) Flow: The Psychology of Optimal Experience. Harper Perennial, New York.

[14] Webster, J., Trevino, L.K. and Ryan, L. (1993) The Dimensionality and Correlates of Flow in Human-Computer Interaction. Computers in Human Behavior, 9, 411-426. Cite Uses Deprecated Parameters (Help). http://dx.doi.org/10.1016/0747-5632(93)90032-N

[15] Cao, X.M. and Liu, X.P. (2008) Positive Psychology from Learned Helplessness to Learned Optimism: Seligman’s Contribution to the Development of Psychology. Advances in Psychological Science, 16, 562-566. 